
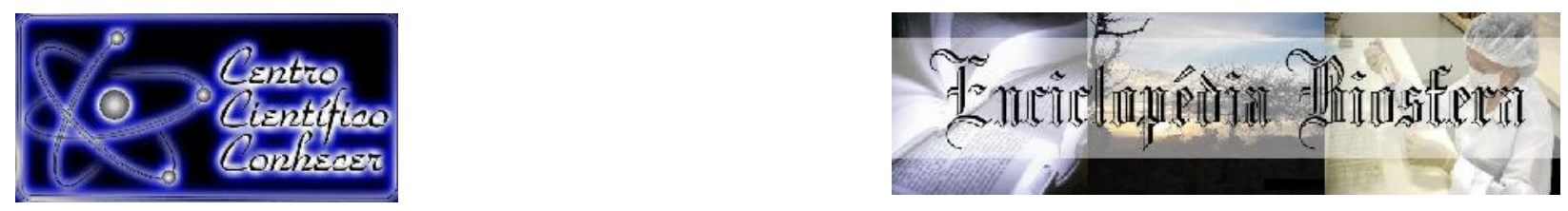

\title{
A INSUSTENTÁVEL CERTEZA DA MORTE: A EUTANÁSIA E O SOFRIMENTO INVISÍVEL
}

\author{
Laleska Rigatto Walder ${ }^{1}$ e Luísa Bueno Coura ${ }^{2}$ \\ ${ }^{1}$ Mestranda em Direitos Humanos da Pontifícia Universidade Católica de São Paulo \\ (PUC-SP), São Paulo - SP, Brasil. \\ E-mail: laleskawalder@gmail.com \\ ${ }^{2}$ Mestranda em Direito Civil Comparado da Pontifícia Universidade Católica de São \\ Paulo (PUC-SP), São Paulo - SP, Brasil.

\section{Recebido em: 15/05/2020 - Aprovado em: 15/06/2020 - Publicado em: 30/06/2020} \\ DOI: 10.18677/EnciBio_2020B56
}

\begin{abstract}
RESUMO
O objetivo central deste trabalho é analisar o direito à morte digna como parte do rol dos direitos fundamentais do indivíduo, estrutura basilar do direito à autonomia e da dignidade da pessoa humana - princípio máximo de qualquer ordenamento jurídico

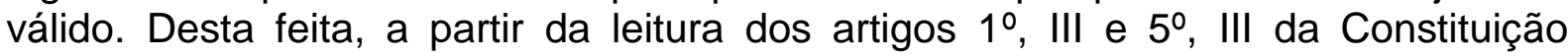
Federal brasileira, bem como da Declaração Universal dos Direitos Humanos, é possível determinar que a vida digna deve perseguir todas as fases da existência de uma pessoa, do nascimento à sua morte. No tocante do objeto, pretende-se focar na possibilidade de aplicação da eutanásia na depressão crônica, enfermidade mental que será apresentada clinicamente em três ramificações: o transtorno depressivo maior, o transtorno depressivo persistente (distimia) e o transtorno depressivo não especificado (depressão atípica) - classificações de alta letalidade e baixa taxa de reversibilidade. Para tal, serão demonstrados, por meio de revisão bibliográfica, as definições teóricas e estatísticas mais recentes acerca do assunto, tratadas pelos diplomas médicos em tela: o Manual Diagnóstico e Estatístico de Transtornos Mentais (DSM-V) e a Classificação Internacional de Doenças para Estatísticas de Mortalidade e Morbidade (CDI-11). Por fim, será realizado um estudo comparativo entre a legislação brasileira e a holandesa e belga, ordenamentos estes que preveem a legitimidade da eutanásia mediante diretrizes médicas de consentimento, voluntariedade e transparência - mencionando-se precedentes de casos onde a eutanásia foi permitida para pacientes de transtornos mentais crônicos. O respeito à autonomia do paciente terminal, dando-lhe a decisão primária de escolher sobre si mesmo provoca, por assim dizer, a ressignificação do sentido de finitude da vida - é, em poucas palavras, resguardar a dignidade do ser humano até seus momentos finais.
\end{abstract}

PALAVRAS-CHAVE: depressão crônica, dignidade da pessoa humana, eutanásia 


\title{
RIGHT TO A DIGNIFIED DEATH: THE POSSIBILITY OF EUTHANASIA APPLICATION IN CHRONIC DEPRESSION
}

\begin{abstract}
The main objective of this work is to analyze the right to dignified death as part of the list of fundamental rights of the individual, the basic structure of the right to autonomy and the dignity of the human person - the main principle of any valid legal system. This time, from reading articles 1, III and 5, III of the Brazilian Federal Constitution, as well as from the Universal Declaration of Human Rights, it is possible to determine that a dignified life must pursue all phases of a person's existence, from birth to death. Regarding the object, we intend to focus on the possibility of applying euthanasia in chronic depression, a mental illness that will be clinically presented in three branches: major depressive disorder, persistent depressive disorder (dysthymia) and unspecified depressive disorder (atypical depression) classifications of high lethality and low rate of reversibility. To this end, the most recent theoretical and statistical definitions on the subject will be demonstrated by means of a bibliographic review, treated by the medical diplomas on screen: the Diagnostic and Statistical Manual of Mental Disorders (DSM-V) and the International Classification of Diseases for Mortality and Morbidity Statistics (CDI-11). Finally, a comparative study will be carried out between Brazilian and Dutch and Belgian legislation, which provide for the legitimacy of euthanasia through medical guidelines of consent, voluntariness and transparency - mentioning precedents of cases where euthanasia was allowed for patients of chronic mental disorders. Respecting the autonomy of the terminal patient, giving him the primary decision to choose over himself, provokes, so to speak, the resignification of the sense of finitude of life - it is, in a nutshell, to safeguard the dignity of the human being until his final moments
\end{abstract}

KEYWORDS: euthanasia, chronic depression, human dignity

\section{INTRODUÇÃO}

Desde os primórdios da sociedade, através da criação de mitos e lendas muito anterior à ascensão das ciências clínicas - é possível observar que a depressão é tão antiga quanto a humanidade. A tristeza acompanha o homem durante toda a sua vida e a melancolia, por assim dizer, é parte da estrutura humana e condição inerente à consciência da morte (MORIN, 1974).

Diferir entre o sentimento de melancolia humano e o quadro patológico - o qual necessita de tratamento médico - trata-se de uma tarefa delicada para pessoas não especializadas em saúde mental. Neste cenário, estigmas e o domínio do tabu sobre o tema levaram à crença de que a depressão não seria uma enfermidade mental, mas consistiria numa deficiência de caráter ou ausência de crença religiosa, podendo ser superada com esforço físico ou espiritual pelo indivíduo (BLEULER, 1985).

Ao mesmo tempo, o direito à morte digna ainda se trata de um tema pouco trabalhado na literatura acadêmica, tampouco no que concerne à esfera do direito, sendo em maioria legislações e ordenamentos jurídicos vedando a execução da eutanásia. Dito isso, pretende-se questionar a aplicabilidade da eutanásia - vista como uma prática ligada diretamente à autonomia e à liberdade individual - no cenário da depressão patológica (FELIX et al., 2013).

A intenção deste trabalho é, portanto, analisar os recortes clínicos da depressão e suas diferentes ramificações, bem como utilizar o direito comparado como ferramenta a fim de estudar as diferentes legislações, no campo nacional e internacional, no que concerne à prática da eutanásia, e por fim, discutir sua 
aplicabilidade no âmbito da bioética no caso da depressão crônica - consagrando-se o direito à morte digna como um direito fundamental e humano (BORCHART; PRUDENTE, 2018).

\section{VISÃO CLÍNICA DA DEPRESSÃO COMO ENFERMIDADE MENTAL}

Ainda vista por parcela da população como uma mera ausência de motivação pessoal, reflexo direto da vida rotineira de trabalho e da fadiga proveniente da interação humana, a depressão é frequentemente subestimada na sociedade, e em decorrência não recebe o tratamento adequado de enfermidade mental. Embora em alguns casos possa se manifestar fisicamente, a depressão apresenta-se também de maneira atípica, dificultando ainda o diagnóstico (MATOS et al., 2006).

Classificada pelo CID-11 (CID-11, 2019) e pelo DSM-V (APA, 2014) - versões mais atualizadas presentemente - na categoria dos transtornos do humor, a depressão é tida como enfermidade de ordem afetiva e deve ser encarada como um problema de saúde pública. No que concerne à duração do surto depressivo, intensidade, recorrência, e potencial lesivo; tais fatores variam de acordo com o tipo de depressão classificada. Consiste em uma das doenças mais comuns da era moderna, o suicídio depressivo é a segunda principal causa de morte entre jovens com idade entre 15 e 29 anos (OPAS, 2018).

Tida como doença mais incapacitante na atualidade, conforme último estudo e dados divulgados pela Organização Mundial de Saúde, em todo o mundo, estimase que mais de 300 milhões de pessoas, de todas as idades, sofram com esse transtorno. Ainda segundo a OMS, o Brasil é campeão de casos de depressão na América Latina: quase $6 \%$ da população, totalizando 11,5 milhões de brasileiros taxa superior à global, que corresponde à $4,4 \%$ da população de todos os países (TUCHLINSKI, 2018). Tratando-se de dados colhidos há dois anos e em tendência gradativa de crescimento, pode-se dizer que esses números se expandiram ainda mais.

No tocante da pesquisa realizada pelo Ministério da Saúde, entre 2015 e 2018, o Sistema Único de Saúde (SUS) registrou aumento de 52\% nos atendimentos ambulatorial e de internação relacionados à depressão, passando de 79.654 para 121.341 procedimentos. Na faixa etária de 15 a 29 anos, o aumento foi de $115 \%$ no mesmo período, evoluindo de 12.698 para 27.363 procedimentos. Esses crescimentos podem ser consequência de uma maior procura das pessoas por assistência ou do aumento de casos na população (OLIVEIRA, 2019).

A causa exata da depressão permanece desconhecida, e as possíveis razões de acometimento ainda são incertas e controversas na literatura clínica. Primordialmente, aponta-se para o desequilíbrio bioquímico, no tocante da produção de endorfina e serotonina, substâncias responsáveis nas sinapses dos neurônios pela produção e controle do estado de humor. Se tratando de um transtorno do humor, a depressão e as demais psicoses são afetadas pelo mal funcionamento dessas substâncias químicas, o que seria resolvido com a administração de antidepressivos (VISMARI et al., 2008).

Contudo, sabe-se que o tratamento farmacológico surte efeitos de maneiras distintas em cada caso, necessitando-se de um olhar individual ao enfermo, bem como de um acompanhamento periódico a fim de se estudar o surgimento ou agravamento da doença. No mais, além dos fatores biológicos ou genéticos que reforçam a vulnerabilidade do paciente, a depressão pode ter origem baseada em fatores psicossociais, resultando de traumas ou condições estimulantes no ambiente social. Existem ainda as causas físicas, decorrentes de acidentes, traumatismos, ou 
até mesmo do uso de medicamentos - ligados ao distúrbio físico sofrido, ou não - e drogas a longo prazo (APA, 2014).

Pensando em um recorte adequado para este trabalho, serão abordadas três classificações clínicas da depressão, com base no Manual Diagnóstico e Estatístico de Transtornos Mentais (DSM-V) - referência médica na atualidade para diagnóstico, tratamento e levantamento estatístico acerca de enfermidades mentais. Entre parênteses será indicado o código utilizado pela Classificação Internacional de Doenças para Estatísticas de Mortalidade e Morbidade (CDI-11), sendo possível não ter código especificado para determinados transtornos (WHO, 2018).

Dito isso, serão trabalhados: o Transtorno Depressivo Maior $\left(\_\right)^{1}$, o Transtorno Depressivo Persistente (6A72) e o Transtorno Depressivo Não Especificado (6A7Z). Como será demonstrado, a escolha se pautou em critérios, como: prevalência, desenvolvimento e curso, fatores de risco e prognóstico, risco de suicídio, consequências funcionais do transtorno e comorbidade.

\section{- Transtorno Depressivo Maior (TDM)}

Conforme supramencionado, o Transtorno Depressivo Maior não possui um código específico da CDI-11. Para sua classificação, o código precisa estar baseado em uma seleção de fatores: recorrência e periodicidade, gravidade atual, presença de características psicóticas e estado de remissão. A gravidade atual e as características psicóticas são indicadas apenas se todos os critérios são satisfeitos atualmente para um episódio depressivo maior (WHO, 2018).

A característica central do TDM baseia-se na duração mínima de duas semanas consecutivas de um episódio depressivo, durante o qual o humor do enfermo é de tristeza e perda de interesse em quase todas as atividades humanas. Em alguns casos, principalmente na infância e adolescência, este sentimento de melancolia pode ser substituído por uma irritabilidade anormal. A irregularidade do sono também é um indicador característico do transtorno depressivo maior, podendo se manifestar por meio da insônia ou hipersonia. Os indivíduos que apresentam sonolência excessiva (hipersonia) podem experimentar episódios prolongados de sono noturno ou de sono durante o dia. Ocasionalmente, a razão pela qual o indivíduo busca tratamento pode ser justamente a perturbação do sono (APA, 2014).

Conforme leitura extraída do Manual Diagnóstico e Estatístico de Transtornos Mentais (2014) o indivíduo também deve experimentar pelo menos quatro sintomas adicionais, que inclui mudanças no apetite ou peso, no sono e na atividade psicomotora; diminuição de energia; sentimentos de desvalia ou culpa; dificuldade para pensar, concentrar-se ou tomar decisões; ou pensamentos recorrentes de morte ou ideação suicida, planos ou tentativas de suicídio (APA, 2014). Isto posto, o diagnóstico para o TDM é especialmente difícil pois muitas vezes os sintomas mencionados também se apresentam como sinais característicos de condições médicas gerais - por exemplo, perda de peso com diabetes não tratado; fadiga com o câncer; hipersonia no início da gravidez; insônia no fim da gravidez ou no pósparto (APA, 2014).

1 No caso do Transtorno Depressivo Maior, embora haja embasamento literário acerca de sua existência, não se aplicam os códigos da CDI-11 para sua classificação. Conforme leciona o Manual Diagnóstico e Estatístico de Transtornos Mentais (APA, 2014): "para alguns transtornos, o código pode ser indicado apenas de acordo com o subtipo ou 0 especificador". 
No que diz respeito à mortalidade do transtorno depressivo maior, trata-se de uma das mais altas dos quadros de distúrbios de humor, mas não se resume à ocorrência do suicídio - embora em boa parte nele esteja contabilizada. A alta taxa de mortalidade dos indivíduos portadores de TDM também pode estar relacionada aos demais sintomas da própria doença, como no caso da ausência de apetite, apatia e desinteresse para necessidades básicas e a consequente influência nas atividades psicomotoras (APA, 2014).

Além disso, a herdabilidade é de aproximadamente $40 \%$, e o traço de personalidade neuroticismo representa uma parte substancial dessa propensão genética. Em outras palavras, os familiares de primeiro grau de indivíduos com transtorno depressivo maior têm risco duas a quatro vezes mais elevado de desenvolver a doença que a população em geral. A comorbidade é alta no TDM, podendo estar ligada a transtornos relacionados a substâncias químicas, ataques de pânico, transtorno obsessivo-compulsivo (TOC), anorexia nervosa, bulimia nervosa e transtorno da personalidade borderline (APA, 2014).

A respeito da recuperação do enfermo, trata-se de um campo delicado e incerto no caso do transtorno depressivo maior. Isso se deve, pois, a recuperação está intimamente ligada a um tratamento precoce, ou seja, o paciente deve ser tratado logo após o diagnóstico do transtorno - situação rara levando em consideração o diagnóstico tardio da depressão e a ausência de tratamento na grande maioria dos casos. O Manual Diagnóstico e Estatístico de Transtornos Mentais (DSM-V) coloca a recuperação em números:

A recuperação em geral começa dentro de três meses após o início para dois em cada cinco indivíduos com depressão maior e em um ano para quatro em cada cinco. O início recente é um forte determinante da probabilidade de recuperação em curto prazo [...]. As características associadas a taxas mais baixas de recuperação, além da duração do episódio atual, incluem características psicóticas, ansiedade proeminente, transtornos da personalidade e gravidade dos sintomas (APA, 2014, p. 165 - grifo das autoras).

Assim como na distimia, o transtorno depressivo maior é duas vezes mais comum em mulheres do que em homens e é mais comum em pessoas solteiras (KORNSTEIN et al., 2000). Entretanto, a distimia e a depressão maior são fenômenos que têm forte relação entre si. Segundo os estudos de Hagop Akiskal (1994), a maioria dos pacientes distímicos irá desenvolver, em algum ponto da vida, episódios de TDM, sendo que alguns trabalhos mostram que quase todos o terão. Estima-se, ainda, que $40 \%$ dos pacientes com episódios de TDM também satisfaçam os critérios para transtorno distímico.

Cordás et al. (1997) apresentam em seus estudos os seguintes dados: $42 \%$ dos pacientes distímicos têm depressão maior, e 28\% dos pacientes com depressão maior possuem distimia. $O$ cenário que contempla tais pacientes é denominado "depressão-dupla", isto é, quando outras variedades de estados do humor depressivo compartilham os mesmos sintomas e respondem a um tratamento farmacológico similar, apesar de cada um ter seu prognóstico específico (SADOCK et al., 2016).

\section{- Transtorno Depressivo Persistente (Distimia)}

A distimia pode ser entendida como a forma crônica e incapacitante de depressão, ocorrendo em uma parcela substancial da população - 3 a $6 \%-e$ 
desencadeando, muitas vezes, o transtorno depressivo maior (GRIFFITHS et al., 2000). Tal modalidade se diferencia da anterior principalmente em razão da periodicidade, uma vez que a distimia é um humor depressivo que possui prevalência na maior parte do dia, na maioria dos dias, pelo período mínimo de dois anos (ou por pelo menos um ano no caso de crianças e adolescentes). Desta feita, os indivíduos cujos sintomas satisfazem os critérios para transtorno depressivo maior por dois anos devem receber diagnóstico de transtorno depressivo persistente, além de transtorno depressivo maior (APA, 2014).

Em termos evolucionários, autores apontam que a distimia surgiu a partir da necessidade de adaptação do humor no enfrentamento de estados catatônicos de estresse e carências, muito em razão da expansão da urbanidade e dos laços superficiais da modernidade líquida. Em outras palavras, o subtipo do transtorno depressivo persistente poderia servir de escudo àqueles que buscam vantagens evolucionárias para condições específicas de risco de vida, sendo, por exemplo, a falta de ação e iniciativa como melhor cenário para proteção pessoal (NESSE, 2000).

Tais características de humor poderiam ter sido benéficas em determinadas comunidades e ambientes sociais, selecionando-os com o passar do tempo. Contudo, em se tratando de uma condição mal adaptativa, a distimia se manifesta clinicamente com letargia, fadiga e fuga de confrontamento (AKISKAL, 1996). Podese concluir que a manutenção dos padrões de gênero, os quais prezam pela submissão e inércia das mulheres, justificariam a dominância feminina nas estatísticas de distimia e depressão (KORNSTEIN, 2002).

A etiologia da distimia é complexa e multifatorial, estando envolvidos mecanismos etiológicos biológicos e psicológicos. Esses fatores múltiplos hereditariedade, predisposição, temperamento, fatores de vida, estressores biológicos, gênero etc. - convergem na produção da desregulação do sistema de recompensa (SPANEMBERG;JURUENA,2004). Eventos de vida estressantes e traumáticos na infância são muito frequentes. A respeito da incidência nos primeiros anos de vida, o Manual Diagnóstico e Estatístico de Transtornos Mentais também aborda a prevalência no tempo:

O transtorno depressivo persistente com frequência apresenta um início precoce e insidioso (i.e., na infância, na adolescência ou no início da idade adulta) e, por definição, um curso crônico. Entre os indivíduos com transtorno depressivo persistente e transtorno da personalidade borderline, a covariância das características correspondentes ao longo do tempo sugere a operação de um mecanismo comum. [...] Os sintomas depressivos têm muito menos probabilidade de desaparecer em determinado período de tempo no contexto do transtorno depressivo persistente do que em um episódio depressivo maior. (APA, 2014, p. 170 - grifo das autoras).

O transtorno depressivo persistente está diretamente ligado ao aumento de utilização dos serviços de saúde, influenciando no crescimento do consumo de drogas psicotrópicas, e assim gerando altos custos financeiros para o tratamento (WESTERMEYER et al., 1998). O consequente risco de hospitalização somado à diminuição da produtividade no trabalho trata-se de fatores que incrementam o custo econômico e social dessa enfermidade, tornando-a uma questão de saúde pública. A grande taxa de comorbidade com outras doenças psiquiátricas - isto é, de $77 \%$ 
dos distímicos - acentua ainda mais a importância do diagnóstico correto da distimia em razão do alto potencial de letalidade (MORENO; MORENO, 1997).

\section{- Transtorno Depressivo Não Especificado (Depressão Atípica) .}

A depressão atípica foi utilizada no passado para designar várias condições diferentes, incluindo depressão não-endógena, depressão secundária a outra condição, depressão associada à ansiedade e pânico, e depressão com características biológicas reversas. No entanto, como o conceito evoluiu, a atipicidade foi definida de forma mais estrita na DSM-V, tratando-se como transtorno depressivo não especificado (APA, 2014).

Se diz não atípica pois o transtorno depressivo neste cenário não pode ser classificado de acordo com os sintomas mencionados anteriormente, tornando o diagnóstico - tanto para o enfermo, quanto para o profissional - significantemente dificultado. A depressão atípica, portanto, possui marcadores distintos, e em sua maioria opostos, das duas classificações anteriores, sendo eles:

a) reatividade do humor (o humor melhora em resposta a eventos positivos reais ou potenciais);

b) duas (ou mais) das seguintes características:

i. ganho de peso ou aumento do apetite significativos;

ii. hipersonia;

ii. paralisia "de chumbo" (sensação de peso nos braços ou nas pernas);

iv. um padrão persistente de sensibilidade à rejeição interpessoal (não limitado aos episódios de perturbação do humor) que resulta em prejuízo social ou profissional significativo;

v. não são satisfeitos os critérios para "com características melancólicas" ou "com catatonia" durante o mesmo episódio (APA, 2014, p. 185/186).

Em geral, pode-se dizer que os pacientes diagnosticados com depressão atípica demonstram um início mais precoce da doença, muitas vezes sendo relatado na infância com comorbidade elevada para distimia, abuso de substâncias químicas (ilícitas ou não) e sociopatia (APA, 2014). Sullivan et al. (1998) utilizaram dados de uma grande Pesquisa Nacional de Comorbidade nos EUA e, detectaram a comorbidade da depressão atípica a outras síndromes como: transtornos de conduta, fobia social; dependência interpessoal e baixa autoestima; e transtornos de abuso de álcool/drogas dos pais.

No que diz respeito à predominância feminina no transtorno depressivo atípico, a proporção de mulheres acometidas é maior do que os números masculinos, bem como pode-se observar o fator hereditariedade - isto é, uma incidência de depressão atípica significativa nas famílias dos enfermos. Dado os sintomas antagônicos aos quadros depressivos melancólicos, a depressão atípica muitas vezes é identificada apenas quando atinge um grau alto de gravidade: situação em que o número de sintomas está substancialmente além do requerido para fazer o diagnóstico, a intensidade causa grave sofrimento e não é manejável, fazendo com que os sintomas interfiram acentuadamente no funcionamento social e profissional (MATOS et al., 2006).

\section{EUTANÁSIA: NO BRASIL E NO MUNDO}

Quando se trata de eutanásia, não é demais recorrer à definição, cuja expressão, emprestada da Grécia Antiga, significa "a boa morte”. Hoje, a eutanásia 
significa a permissão e até mesmo o auxílio para apressar a morte de alguém em estado de sofrimento (SADOCK et al., 2016). O recurso à eutanásia dá-se em busca do alívio de um sofrimento muito grande, na maioria das vezes prolongado e, necessariamente, fatal e irreversível. Então, visando abreviar a dor, quando a morte se mostrar inevitável (ABREU, 2015).

A eutanásia é um tema que suscita discussões há muitos séculos, talvez desde o início da humanidade; e sua prática é um fato, embora ainda seja considerada um crime em praticamente todos os ordenamentos jurídicos e a abordagem seja um verdadeiro tabu (CORRÊA, 2019). A morte já se trata de um assunto "proibido", do qual as pessoas tentam constantemente se esquivar. Todavia, tal comportamento social parece no mínimo contraditório, uma vez que a morte se trata da única certeza enquanto seres vivos. Todo ser que nasce há de morrer esse é um processo natural e certo. O crescimento, o desenvolvimento e o envelhecimento podem não acontecer, a morte pode se antecipar, mas a finitude da vida será sempre uma certeza. No entanto, ao invés do tema ser abordado com a naturalidade que merece, é frequentemente motivo de grande angústia e negação, razão pela qual se caminha a passos lentos qualquer possível mudança de paradigma (ABREU, 2015).

Outro aspecto desse comportamento negacionista da finitude enquanto ser humano, trata-se do aumento desmedido de meios de manutenção da vida, ou da não-paralisação da atividade cerebral (FELIX et al., 2013). Certamente, a dificuldade, não só da abordagem do tema, como também e, principalmente, da aceitação do mesmo, deve-se à ética religiosa, que se encontra arraigada no indivíduo, assim como na sociedade (ABREU, 2015).

Em Atenas, o Senado podia determinar a morte através de uma bebida venenosa ministrada em cerimônias especiais, para pessoas idosas e com doenças incuráveis; na Idade Média, era oferecida a "misericórdica" aos guerreiros feridos, um punhal afiado para que encurtassem a dor e evitar a desonra. Veja-se que a eutanásia fora admitida na Antiguidade, todavia passou a ser condenada a partir do judaísmo e do cristianismo, que tem na vida o caráter sagrado e intocável. No direito moderno, portanto, o que era repelido moralmente passa a ser condenado criminalmente (FRANÇA, 2019).

Se o argumento contra a eutanásia se deve a um entrave social baseado numa moral religiosa, o argumento a favor da mesma baseia-se em um dos princípios fundamentais a qualquer religião: a compaixão com aquele que sofre. $A$ ética médica também se demonstra um impeditivo de peso na possibilidade de aceitação da eutanásia, saliente-se que: a Associação Mundial de Medicina considera a eutanásia um procedimento inadequado do ponto de vista médico. (ABREU, 2015).

O comprometimento do profissional da medicina não é outro, senão a manutenção da vida; todavia, cabe o questionamento: a qualquer custo? (FRANÇA, 2019). Maria Berenice Dias, apresenta o posicionamento do Papa Pio XII, em um Congresso de Anestesiologia em Roma quando questionado sobre a obrigação dos médicos na tentativa de manter vidas: "até o limite de uso dos meios normais, não sendo necessário o uso de métodos excepcionais." (DIAS, 2009).

Sabe-se que, no Brasil, assim como na maioria dos países, a eutanásia continua sendo enquadrada como tipo penal, como homicídio qualificado ou suicídio assistido, a depender da condição volitiva e de manifestação do paciente (CORRÊA, 2019). Contudo, em algumas legislações, a aplicação da eutanásia é legal perante casos específicos, como será abordado no decorrer deste trabalho. 
A eutanásia encontra várias definições, que serão brevemente explanadas a seguir. A princípio e de modo amplo, designa o suicídio realizado mediante ajuda médica, ao paciente que se encontra em sofrimento prolongado e irremediável; deve haver uma ação de um médico especialista de maneira controlada, que atua diretamente para causar a morte do paciente (ABREU, 2015). Todavia, a essa definição genérica se acrescentam algumas especificidades, acarretando uma diversa classificação que deve ser observada (SADOCK et al., 2016).

A eutanásia pode ser um procedimento cuja iniciativa dê-se pelo próprio paciente, ou seja, eutanásia voluntária (SADOCK et al., 2016). O próprio paciente, plenamente capaz de sua vontade, requer que se dê a abreviação de sua vida, mediante uma situação irreversível e na eminência da morte (perspectiva de vida de seis meses); desejando tornar menos longo e doloroso o processo da morte. Para que haja eutanásia voluntária, o paciente deve, portanto, manifestar sua vontade de forma clara e incontestável. Tal manifestação pode ocorrer quando da aproximação da morte, ou por algum documento previamente redigido, em que o paciente tenha declarado a sua vontade, em caso de eventual impossibilidade posterior (COMMISSION FÉDÉRALE DE CONTRÔLE ET D'ÉVALUATION DE L'EUTHANAISE, 2016/2017). Veja-se que, através dessa manifestação fica autorizada a eutanásia; no Brasil, manifestação prévia do paciente, por testamento vital ou consentimento informado, por exemplo, pode autorizar a ortotanásia (FELIX et al., 2013).

A eutanásia voluntária, como é o caso, pode ser confundida com suicídio assistido, embora haja uma diferença crucial: 0 agente. A eutanásia, necessariamente, deve ser praticada por outro indivíduo, que não seja o paciente, o que pode ocorrer, por exemplo: por falta de capacidade física de fazê-lo ou por ignorar a maneira como se deve ministrar a injeção letal ou a dosagem da substância a ser ingerida (SADOCK, et al., 2016).

No suicídio assistido, o próprio paciente dá fim à sua vida. Ingerido alguma droga ou medicamento em dose elevada, de modo que se dê o efeito fatal, tendo-lhe ajudado algum parente ou pessoa próxima (SADOCK et al., 2016).Todavia, no ordenamento jurídico nacional, ambas as hipóteses poderiam ser compreendidas no tipo descrito pelo artigo 122 do Código Penal ${ }^{2}$, como indução ou auxílio ao suicídio (BRASIL, 1940).

A eutanásia pode se classificar como involuntária, quando a decisão é tomada sem o consentimento do paciente (SADOCK et al., 2016); quando, por exemplo a família ou o médico decide pelo paciente, por absoluta ausência de capacidade do mesmo de manifestar sua vontade; ou por falta de uma manifestação prévia. Nesse caso, no ordenamento jurídico brasileiro tem-se tipificado, nessa situação, o homicídio (BRASIL, 1940); que, por parte da doutrina, pode ser tido como privilegiado, sendo um homicídio piedoso, justificado pelo relevante valor moral (CORRÊA, 2019). Nesse sentido, pode-se observar nas decisões judiciais que quando identificada a eutanásia haverá homicídio, mas um homicídio privilegiado,

2 Art. 122 - Induzir ou instigar alguém a suicidar-se ou prestar-lhe auxílio para que o faça:

Pena - reclusão, de dois a seis anos, se o suicídio se consuma; ou reclusão, de um a três anos, se da tentativa de suicídio resulta lesão corporal de natureza grave.

Parágrafo único - A pena é duplicada:

Aumento de pena

I - se o crime é praticado por motivo egoístico;

II - se a vítima é menor ou tem diminuída, por qualquer causa, a capacidade de resistência (BRASIL, 1940).

3 Artigo 121, Código Penal (BRASIL, 1940). 
com pena menor, com base com preceito moral, que pode ser uma atenuante, mas não uma excludente de ilicitude (ABREU, 2015).

No Uruguai, por exemplo, existe a legislação, lei no 9.414 de 19 de junho de 1934, que estabelece o perdão judicial no caso de eutanásia, uma vez que tenha sido o seu autor convencido pela vítima e tomado por motivos de piedade, o chamado homicídio piedoso (URUGUAI, 1934) ${ }^{4}$.

Saliente-se que são variados os posicionamentos sociais e jurídicos quanto a eutanásia, enquanto em alguns países, como o Brasil é tipificada como homicídio, embora com pena reduzida; há países em que a prática é legalizada, como na Holanda, Bélgica, Luxemburgo, Suíça, Canadá, Colômbia e alguns estados dos Estados Unidos (ABREU, 2015; SADOCK et al., 2016).

Outra classificação quanto a eutanásia dá-se em relação à atividade: sendo ativa ou passiva. Na eutanásia ativa há prática de atos necessários à abreviação da vida, ou seja, são ministrados os meios para causar a morte; enquanto, na eutanásia passiva há interrupção das medidas médicas imprescindíveis ao salvamento, à manutenção ou à prorrogação da vida (SADOCK et al., 2016).

A eutanásia passiva é também denominada ortotanásia, quando diante da inevitabilidade da morte, opta-se por interromper tratamentos médicos sem resultado, isto é, quando já não suscitam nenhum efeito e o paciente, mediante respaldo médico, aceita a aproximação da morte (FELIX et al., 2013).

Quanto à voluntariedade da eutanásia e à sua atividade, para ilustrar, tem-se dois e casos, que chegaram à Suprema Corte americana na década de 1990: no primeiro caso, os familiares de Cruzan ingressaram com o pedido de desligamento dos aparelhos que a mantinham viva, o que caracteriza a eutanásia passiva. A Corte, na ocasião, entendeu que existia a possibilidade de serem retirados os recursos que prolongavam a vida da paciente, se os familiares provassem que nesse sentido havia se manifestado a própria antes de restar inconsciente, ou seja, autorizaria a eutanásia passiva, se essa fosse comprovadamente voluntária (MARMELSTEIN, 2019).

No outro caso, um paciente tetraplégico e em estado terminal, plenamente consciente, ingressou ele mesmo com um pedido ao judiciário de que fosse autorizada a sua morte por meio de medicação capaz de abreviar sua vida, que serIhe-ia dada por um médico (eutanásia ativa), tal pedido fora autorizado, sem qualquer condição, pois desde o princípio estava caracterizada a eutanásia voluntária (MARMELSTEIN, 2019).

Na decisão favorável ao pedido, a Corte afirmou que:

[...] assim como na decisão de fazer ou não um aborto, a decisão de como e quando morrer, é uma das 'mais íntimas escolhas pessoais que uma pessoa pode fazer na vida', uma escolha que é o centro da dignidade e autonomia pessoais. (Suprema Corte Americana apud MARMELSTEIN, 2019, p. 45 - grifo das autoras).

Diametralmente oposta a essa situação, tem-se a distanásia, que se caracteriza pelo prolongamento da vida através do uso desproporcional de recursos extraordinários da medicina, quando não produzem mais nenhum benefício terapêutico, apenas acarreta frustração e dor, dilatando o sofrimento da espera pela

4 Artigo 37 - Del homicidio piadoso: Los Jueces tiene la facultad de exonerar de castigo al sujeto de antecedentes honorables, autor de un homicidio, efectuado por móviles de piedad, mediante súplicas reiteradas de la víctima (URUGUAI, 1934). 
morte (FELIX et al., 2013). Nessa situação não há preocupação com a qualidade e dignidade da vida do paciente, prolonga-se a vida apenas por fixação médica em fazê-lo (MELO, 2016).

Saliente-se que a proporcionalidade no uso de recursos médicos capazes de manter a vida, diante de tantos avanços científicos e tecnológicos, que disponibilizam cada vez mais terapias, é subjetivo e de difícil precisão. Todavia, mostra-se fundamental e decisivo impor-se esse questionamento: qual o limite da manutenção da vida? (DIAS, 2009). Mostra-se urgente que tal discussão receba a devida atenção no meio jurídico, que busque compreender e delimitar o uso dos métodos artificiais de prolongamento da vida, quando essas forem apenas meios de dilatação de uma vida doente a que o paciente está sujeito sem possibilidade de reversão dessa condição (MELO, 2016).

Conforme o questionamento de Dias (2009), o crescente desenvolvimento da medicina, seus inúmeros tratamentos e meios de criar uma sobrevida, o ser humano poderia ser praticamente eternizado por meio de aparelhos ou testes de medicamentos psiquiátricos, por exemplo, mas: é ético manter uma vida cuja possibilidade de cura seja praticamente nula?

A tal questionamento, mostra-se crucial o recurso aos quatro princípios básicos, norteadores da Bioética, segundo Maria Berenice Dias (2009), da não maleficência, da beneficência, da autonomia e da justiça. Segundo ensina a autora, a não maleficência significa não fazer o mal, ou seja, na área médica pode-se interpretar como não receitar tratamentos inapropriados ou praticar atos desnecessários, ter cuidado com o paciente e conhecer a sua condição (DIAS, 2009).

Beneficência é fazer o bem. No caso da ética médica pode-se interpretar como empregar os meios possíveis e assegurar o emprego da melhor técnica, visando sempre o bem-estar do paciente (DIAS, 2009). Esses dois princípios encontram-se traduzidos no artigo VI do Código de Ética Médica, que assim prevê:

\begin{abstract}
VI - O médico guardará absoluto respeito pelo ser humano e atuará sempre em seu benefício, mesmo depois da morte. Jamais utilizará seus conhecimentos para causar sofrimento físico ou moral, para o extermínio do ser humano ou para permitir e acobertar tentativas contra sua dignidade e integridade (BRASIL, 2018).
\end{abstract}

Com base nesses dois princípios já se pode alcançar um limite, embora ainda subjetivo, sobre o tratamento. Prolongar uma vida sofrida sem quase nenhuma perspectiva de melhora é um comportamento que definitivamente não promove o bem, ao contrário, apenas aumenta o sofrimento (PRESSLY, 2018).

Segundo o princípio da autonomia, o paciente, plenamente capaz e dotado de sua racionalidade, pode deliberar sobre seu corpo, sua vida, como e quais os limites dos tratamentos que gostaria: estabelecer os limites em que gostaria de ver respeitada sua vontade em situações fronteiriças. Cabe aos médicos o respeito à tomada de decisão informada do paciente e a obediência às escolhas dos pacientes e o cumprimento dos atos segundo a vontade daqueles (DIAS, 2009).

Esse princípio, tão caro ao tema pelo presente trabalho apresentado, é determinante para a sua aceitação ou não. O respeito à autonomia e à autodeterminação compõe a dignidade da pessoa, princípio Constitucional, presente no artigo $1^{\circ}$, Ill da Carta Magna e, ainda, em outros dispositivos, a exemplo de alguns incisos do artigo 5으 do mesmo diploma (BRASIL,1988). 
Tão importante quanto o direito à vida é o direito à dignidade humana. A vida a que se refere a Constituição Federal e todo o ordenamento jurídico nacional não é limitada ao conceito biológico, inclui a amplitude social e psicológica para a qual mostra-se fundamental a dignidade. Sendo a autonomia e a liberdade, como já se disse, parte essencial da dignidade, não há que se falar em vida digna sem que aquelas sejam respeitadas. A dignidade humana e a autonomia, como parte daquela, fundamentais à vida, deveriam sê-lo também à morte, como parte da vida que é (FELIX et al., 2013).

Tem-se, ainda, o princípio da justiça, que requer do profissional da saúde um olhar equânime sobre seus pacientes, dando-lhes, independente de aspectos sociais, econômicos ou religiosos, o mesmo tratamento: os recursos devem ser equilibradamente distribuídos, com o objetivo de alcançar, com melhor eficácia, o maior número de pessoas assistidas (DIAS, 2009).

Transferindo esse princípio para a análise da eutanásia, é possível incorrer no erro de interpretá-la de forma utilitarista. Todavia, deve-se encarar o fato de que a vida prolongada sem possibilidade de cura e com morte iminente - isto é, aquela dependente de tratamentos médicos impeditivos de uma vida saudável e "normal" é, além de dolorida e sofrida, muito custosa. Por isso, a manutenção econômica do tratamento da depressão crônica pode estar distante da realidade e das possibilidades da maioria dos pacientes e suas famílias. Dito isso, é possível afirmar que em, em prol de uma tida "ética médica", deve-se escolher uma vida que valha mais com base nas possibilidades de arcar ou não com os altos custos pelo próprio paciente? (DIAS, 2009).

Se a discussão quanto à eutanásia já é dificultosa quando se trata de pacientes com doenças terminais como câncer ou doenças degenerativas, ou, ainda, em situações de pacientes em coma ou com graves sequelas de acidentes; mais delicada é a abordagem da eutanásia em casos de doenças psicológicas, como em quadros graves e prolongados, muitas vezes por toda a vida, de depressão ou de outras doenças que a tenham causado ou intensifiquem. Antes de adentrar nessa temática, no entanto, será explanado brevemente o cenário da eutanásia no mundo (PRESSLY, 2018).

Para tanto deve-se começar com a Holanda, o primeiro país a legalizar a eutanásia em 2002. A legalização, no país, foi fruto de um longo processo, que deu início em 1973 com a absolvição de uma médica que havia praticado a eutanásia; em 1984, a Associação Médica Holandesa emitiu critérios orientadores aos médicos sobre a prática, para, então culminar na legislação de 2002 (LORDA; CANTALEJO, 2012).

Já na Bélgica, o processo de legalização foi muito mais célere, não haviam, antes da legislação, jurisprudências significativas quanto ao tema, apenas discussões doutrinárias esparsas devido ao caso emblemático holandês, de 1973; a discussão tomou corpo em 1994, quando alguns projetos de lei foram encaminhados ao Parlamento belga, sendo concluída e promulgada a lei também em 2002. A legalização desses países apresenta semelhanças, como também algumas diferenças (LORDA; CANTALEJO, 2012).

Em Luxemburgo, a legalização veio apenas em 2009, com uma legislação muito próxima à belga. Saliente-se que esses três países firmaram na Segunda Guerra Mundial, um acordo econômico e comercial que os uniu num grupo Benelux, precursor da futura União Europeia. Veja-se que há proximidades sociais e culturais entre esses países o que justifica a postura com relação ao tema. Em ambos os 
países foram legalizados a eutanásia e o suicídio assistido, hipóteses em que se requer a assistência médica (LORDA; CANTALEJO, 2012).

Por se tratar de um tema tão delicado, a Associação Médica Holandesa estabeleceu diretrizes rígidas e requisitos que devem ser observados para que seja aceito o pedido de eutanásia de um paciente, como por exemplo: 1) que a decisão seja do paciente e sua solicitação seja voluntária, não cabendo ao médico em nenhuma hipótese essa sugestão; 2) o paciente deve possuir informações médicas necessárias sobre sua condição de saúde, sobre as possibilidades terapêuticas, bem como se sua condição é irreversível e irremediável; 3) o paciente deve estar passando por um sofrimento insuportável; 4) médico e paciente devem estar concordes com a falta de alternativa terapêutica proporcional ao paciente; 5) deve haver uma segunda avaliação da condição do paciente, por outro médico que seja imparcial e neutro, para que possa atestar a presença dos requisitos para a prática da eutanásia; 6) médico deve abreviar com a vida do paciente de maneira medicamente apropriada (ABREU, 2015), que seja breve e não cause dor ao paciente.

Também na Bélgica os requisitos são muito próximos. Observe-se que ambas as legislações deixam claro que nenhum médico é obrigado a praticar a eutanásia se não concorda com a mesma, isso porque, nem mesmo naqueles países a prática é unanimemente aceita (COMMISSION FÉDÉRALE DE CONTRÔLE ET D'ÉVALUATION DE L'EUTHANAISE, 2016/2017).

Outras são as legislações que autorizam a eutanásia, mas o presente trabalho se ateve à Holanda e à Bélgica por serem países em que se autoriza inclusive a eutanásia em caso de doenças psiquiátricas (PRESSLY, 2018). O médico responsável por um caso emblemático na Holanda menciona algo importante a ser observado: diversos pacientes psiquiátricos em um contexto de total desesperança, tendo já tentado todos os tratamentos possíveis, sem mais observar a melhora, comentem suicídio; não poderiam, portanto, ser considerados pacientes terminais? (AVIV, 2015).

Uma paciente Belga que optou pela eutanásia mencionou pouco antes de tomar a decisão que havia perdido o seu levensperspectief, ou seja, o seu sentido de vida ${ }^{5}$. Godelieva foi uma mulher belga que viveu com depressão desde sua adolescência, oscilando em fases melhores ou piores, mas optou já avó, depois dos 60 anos que não valeria mais a pena lutar por uma qualidade de vida que não encontrava, pois encontrava-se mais uma vez e de forma profunda, numa grande depressão (PRESSLY,2018). Ora, um paciente que tenha vivido sempre em busca de tratamentos sem nunca ter alcançado uma definitiva melhora, não encontrando razão para viver, mergulhado num sofrimento verdadeiramente profundo, não merece o descanso contra essa luta, se assim o desejar? (AVIV, 2015).

As opiniões se dividem também nesses dois países quanto à eutanásia em caso de doenças psiquiátricas, mas elas são legais. Ocorrem em menor número que a eutanásia em caso de doenças físicas, pois demandam um estudo mais detido sobre o caso, como por exemplo, a presença de uma terceira opinião médica e o acompanhamento do paciente por um período mais prolongado, bem como a

5 "She felt that she had lost her levensperspectief, a Dutch word that refers to the sense that there is something to live for." 
constatação de que já tenha passado por todos os tratamentos psiquiátricos possíveis e ainda assim não tenha havido melhora (PRESSLY, 2018).

Deve-se, então, partir brevemente para o objeto principal do presente trabalho: a possibilidade de eutanásia em caso de depressão. Nas palavras de Aurelia Brouwers, jovem holandesa que optou pelo suicídio assistido, depois de uma longa e penosa luta contra a depressão, diagnosticada aos seus 12 anos e dizia não ter nunca conhecido a felicidade: precisamos nos livrar do tabu de que você deve permanecer sempre em tratamento, até o amargo fim. (PRESSLY, 2018).

\section{APLICAÇÃO DA EUTANÁSIA NA DEPRESSÃO CRÔNICA}

Se a finitude da vida ainda é vista como um tabu, a provocação voluntária da morte é uma barreira silenciosa e impenetrável na sociedade. Os ritos, tradições de passagem e crenças religiosas pregam, muitas vezes, a penalização daqueles que flertam com a morte. Na cultura cristã os castigos são inúmeros: o fogo eterno, o purgatório aos suicidas e, por vezes, o encargo da reencarnação para reconciliar o ato cometido. Em alguns casos, o castigo supera as fronteiras espirituais: não se pode enterrar os suicidas em solo sagrado, proibindo-se o enterro em cemitérios familiares - provocando, inclusive, a imagem de indulgência para aqueles que se atreveram a cessar espontaneamente a sua vida (CARNEIRO et al., 2019).

$\mathrm{O}$ homem moderno insiste em negar a morte. $\mathrm{O}$ apego material ao corpo e à imortalidade utópica demonstram como o meio social ainda é impregnado de sentimentos de censura à realidade; remove-se o debate sobre a morte do cotidiano, dos pensamentos íntimos, dando-lhe lugar a um esquecimento absoluto (HEIDEGGER, 2015). Citando Freud, Morin (1974) ilustra a negação constante da morte em sua forma ocasional, cenário em que, para os homens, morrer apenas ocorre por acidente. Ou seja, atribui-se morrer ao fortuito, enfermidades, infecções, velhice avançada; o que revela claramente a tendência de despojar a morte de todo o caráter de necessidade ou urgência - fazendo dela um acontecimento meramente acidental.

O direito, como ferramenta humana de poder, não escapa dessa corrente ideológica. O ordenamento jurídico brasileiro - em tendência internacional - ainda não reconhece o direito à morte digna que, em síntese, pode ser definido como o direito de auto manifestação da pessoa sobre sua própria vida, decidindo por si mesmo quando e como findá-la. Tal direito não se trata meramente do ato de morrer, mas também engloba o direito à informação sobre seu quadro de saúde atual e futuro, suas alternativas de tratamento, bem como a recusa iminente de medicamentos ou cuidados paliativos. Nesse sentido, a eutanásia seria um direito proveniente da autonomia humana (RIDOLPHI; RANGEL, 2017).

No que tange aos cuidados paliativos, a discussão - embora embrionária e a passos lentos - existe no Brasil. Como já mencionado, a ortotanásia que se trata da recusa ou limitação de tratamentos que prolongam a vida do doente terminal, cuja enfermidade seja grave e incurável, respeitando-se a vontade do paciente ou de seu representante legal. A previsão, constitucionalmente declarada, encontra-se amparada na Resolução no 1.805/2006 do Conselho Federal de Medicina (BRASIL, 2006). No viés da Bioética e Biodireito, D’Agnol ressalta a importância da autonomia do paciente ao optar por uma morte digna:

A boa morte (eutanásia), a morte escolhida, não deve ser vista como algo antinatural ou contrário às leis divinas. Respeitando a autonomia, é possível ter uma atitude menos mitificadora perante a morte. [...] A decisão de morrer ou não cabe à pessoa que, no pleno 
uso de suas faculdades, pode prever uma forma digna de deixar a existência especificando claramente o que deve ser feito caso atinja um estado em que a vida não pode mais ser plenamente vivida (DALL'AGNOL, 2015, p. 25 - grifo das autoras).

Pode-se dizer que uma das conquistas mais importantes da humanidade foi da laicidade estatal e, sem esta, não seria possível a permanência e proteção do direito à liberdade religiosa, cuja importância é presente em muitos cenários da vida cotidiana. No acórdão que tratou da questão do aborto de fetos anencéfalos, ao abordar a separação entre Estado e Religião, o Ministro Marco Aurélio (2012) assim se pronunciou:

Se, de um lado, a Constituição, ao consagrar a laicidade, impede que o Estado intervenha em assuntos religiosos, seja como árbitro, seja como censor, seja como defensor, de outro, a garantia do Estado laico obsta que dogmas da fé determinem o conteúdo de atos estatais. Vale dizer: concepções morais religiosas, quer unânimes, quer majoritárias, quer minoritárias, não podem guiar as decisões estatais, devendo ficar circunscritas à esfera privada. [...] Significa que as religiões não guiarão o tratamento estatal dispensado a outros direitos fundamentais, tais como o direito à autodeterminação, o direito à saúde física e mental, o direito à privacidade, o direito à liberdade de expressão, o direito à liberdade de orientação sexual e o direito à liberdade no campo da reprodução (BRASIL, 2012, p. 04 grifo das autoras).

A Declaração Universal sobre Bioética e Direitos Humanos da ONU (2005) dispõe sobre a autonomia e o consentimento individual:

\begin{abstract}
$\underline{5^{\circ} \text {. Autonomia e responsabilidade individual }}$
A autonomia das pessoas no que respeita à tomada de decisões, desde que assumam a respectiva responsabilidade e respeitem a autonomia dos outros, deve ser respeitada. No caso das pessoas incapazes de exercer a sua autonomia, devem ser tomadas medidas especiais para proteger os seus direitos e interesses.

6o. Consentimento

1. Qualquer intervenção médica de carácter preventivo, diagnóstico ou terapêutico só deve ser realizada com o consentimento prévio, livre e esclarecido da pessoa em causa, com base em informação adequada. Quando apropriado, o consentimento deve ser expresso e a pessoa em causa pode retirá-lo a qualquer momento e por qualquer razão, sem que daí resulte para ela qualquer desvantagem ou prejuízo (ONU, 2005, p. 07 - grifo das autoras).
\end{abstract}

A Declaração Universal dos Direitos Humanos (ONU, 1948) solidifica os direitos humanos em três princípios basilares: a) o da inviolabilidade da pessoa - é vedada a imposição de sacrifícios a um indivíduo sob argumento de que resultarão em benefícios a outras pessoas; b) o da autonomia da pessoa - toda pessoa é livre para realizar qualquer conduta, desde que seus atos não prejudiquem terceiros; e c) o da dignidade da pessoa, princípio supremo e norteador de todos os demais direitos fundamentais do indivíduo. A dignidade, por mais complexa que seja sua definição, deverá reger toda a vida e ações de uma pessoa - e qualquer ato que atente contra este valor será afastado e punido. Obrigar alguém a viver em sofrimento é verdadeiramente uma violação à sua dignidade. 
Portanto, o cenário não é de uma colisão de direitos fundamentais, mas sim de um desdobramento destes, isto é, o direito à morte digna vincula-se ao direito de se viver dignamente. Não são conceitos excludentes, mas princípios complementares. A possibilidade de aplicação de eutanásia em depressivos crônicos, nas condições e diretrizes médicas já mencionadas, revela-se uma hipótese decorrente da preservação de sua autonomia e dignidade humana (CUNHA, 2012).

\section{CONSIDERAÇÕES FINAIS}

A doença mais incapacitante do mundo na atualidade, segundo a OMS, ainda é subestimada e, por muitos ignorada. Viu-se que, no Brasil, quase $6 \%$ da população já foi diagnosticada com depressão, são 11,5 milhões de pessoas que sofrem com essa doença e suas consequências (TUCHLINSKI , 2018).

Sabe-se que existem pessoas diagnosticadas com depressão e, com tratamento médico adequado e acompanhamento psicológico, alcançam a melhora na qualidade de vida, podendo até serem de fato curadas. Todavia, essa é uma perspectiva incerta e, dependendo da precisão e tempo do diagnóstico, bem como o consequente início do tratamento, ou ainda, de condições particulares do paciente, pode ser considerada improvável a recuperação.

Pretendeu-se por meio deste trabalho trazer à baila uma discussão que se mostra necessária e eminente; bem como demonstrar a importância de ser abordada a hipótese, com a mesma acuidade que é dada à discussão em caso de doenças físicas, uma vez que o sofrimento dos pacientes com depressão ou outras doenças psíquicas não é menor do que daqueles que passam por doenças físicas.

A eutanásia segue vedada nos diplomas brasileiros, sendo sua prática criminalizada no Código Penal. Cabe dizer que a diferença de tratamento pelos legisladores entre ortotanásia e eutanásia é contraditória, uma vez que a discussão a respeito da primeira afasta concepções de ordem moral, religiosa, social ou política acerca da vida humana. A positivação desse direito demonstra que o Estado, tampouco terceiros, podem decidir qual vida é digna de ser vivida, resguardando-se este poder ao íntimo do indivíduo afetado pela enfermidade irreversível.

A eutanásia, viu-se, quando observado o seu agente é avaliada como um ato de compaixão e, na nossa jurisprudência, tal particularidade é levada em consideração sendo fator de diminuição de pena, uma vez que a prática em si é tipificada como homicídio. Do ponto de vista do paciente que a requer, é considerada um ato de autonomia, como traço fundamental da dignidade, conforme Kant: "a autonomia é, pois, o princípio da dignidade da natureza humana, bem como de toda natureza racional". (KANT, 2013).

Traça-se, dito isso, um paralelo com o artigo 1으. III, da Constituição Federal de 1988, que trata da dignidade humana, e com o artigo 5으. III do mesmo diploma, segundo o qual ninguém será submetido à tortura nem a tratamento desumano ou degradante. Primeiramente, a supremacia da dignidade humana deve percorrer durante a vida sendo, portanto, a morte parte dela. Não se deve esquecer que a dignidade não tange somente o nascimento e envelhecimento do indivíduo, mas contempla igualmente a morte - e se assim o for, deve ser tão digna e autônoma quanto à vida que lhe precedeu. Se esta vida se trata de um verdadeiro martírio para quem a vive; mantê-la em prol de preceitos religiosos ou disposições de terceiros é, em outras palavras, provocar um tratamento desumano, degradante e tortura. 
Ora, cabe observar o que estabelece A Declaração Universal sobre Bioética e Direitos Humanos, de 2005, em seu artigo 3으, que vem de encontro a coroar o que se disse no presente trabalho:

1. A dignidade humana, os direitos humanos e as liberdades fundamentais devem ser plenamente respeitadas. 2. Os interesses e o bem-estar do indivíduo devem prevalecer sobre o interesse exclusivo da ciência ou da sociedade.

Numa sociedade secular e laica não se pode permitir que dogmas individuais de ordem religiosa rejam sobre os demais. Não é legítimo, nem mesmo razoável, obrigar alguém a viver em dor sob o argumento de que a vida é um bem sagrado sustentado por valores divinos. Tampouco cabe o prolongamento da vida utilizandose de meios científicos desproporcionais, quando comprovadamente ineficientes para a recuperação.

Muitos pacientes com depressão encontram-se fadados a um sofrimento vitalício e em respeito a esses pacientes a discussão sobre a eutanásia deve ser estendida também à hipótese de doenças emocionais, como foi abordado no presente trabalho, a depressão maior, a distanásia e a depressão atípica. Além do sofrimento ocasionado, deve-se levar em consideração os custos de uma vida levada através da administração de medicamentos caros, aqui os antidepressivos, ou tratamentos terapêuticos que não demonstram resultado para o indivíduo enfermo.

Não se trata de defender a desistência de todos os esforços pelo desenvolvimento da ciência curativa e dos cuidados com pacientes terminais. Tratase, efetivamente, do reconhecimento da voluntariedade e consentimento daqueles cuja enfermidade possui baixas taxas de reversibilidade - transtornos incuráveis em grande parte dos casos. Reconhecimento que também percorre pela consciência da dor e sofrimento daquele que luta contra a vida.

Ao tratar de transtornos depressivos cuja reversibilidade é improvável e, ao mesmo tempo, o potencial de letalidade é alto, tais fatores pesam mais do que crenças de terceiros. A verdade é que tais pessoas, cuja autonomia é cerceada pelos demais, são invisíveis boa parte do tempo para a sociedade. A dificuldade do diagnóstico e a peculiaridade da doença não podem tornar invisível uma dor que é verdadeira, tampouco diminuí-la ou ser menosprezada a luta dos que com ela sofrem.

Pode haver vida saudável e digna para um paciente com depressão, sim. Mas existe um considerável número de pacientes que, por já ter tentado todos os tratamentos possíveis, não encontra mais qualidade de vida. Tais pacientes, imersos numa profunda desesperança e desgosto, tendo já tentado terapias e múltiplos tratamentos, não sendo mais possível, tão pouco provável a cura de sua doença, seria justo mantê-los em vida? No que sua dor difere da do paciente com doença física terminal? Manter sua existência em prol de terceiros, crenças, ou um tido paternalismo estatal dos corpos, não seria proferir um tratamento degradante e tortura (art. 5으. III, CF/88)?

O que se pode concluir é que, se for da vontade livre e consciente do paciente, dotado de todas as informações médicas sobre sua condição de saúde e perspectiva de vida, diante da inexistência de recursos terapêuticos proporcionais à sua manutenção, sequer possibilidade de melhora; se houver apenas 0 prolongamento do sofrimento e a dilatação do processo de morte; e não havendo mais vida, pela ausência de dignidade e sobreposição da dor, a eutanásia 
representa a autonomia e a compaixão - proporcionando vida à morte, devendo ser uma possibilidade tanto às doenças físicas como emocionais, cabendo-lhe legislação precisa e pormenorizada.

\section{REFERÊNCIAS}

ABREU, F. S. Eutanásia e legislação penal. Âmbito jurídico, 2015. Disponível em: $<$ https://ambitojuridico.com.br/cadernos/direito-penal/eutanasia-e-legislacao-penal/>. Acesso em: 12/05/20.

AKISKAL, H. Dysthymia: clinical and external validity. Acta Psychiatr Scand Suppl, 1994. Disponível em: < https://onlinelibrary.wiley.com/doi/abs/10.1111/j.16000447.1994.tb05879.x>. DOI: 10.1111/j.1600-0447.1994.tb05879.x

AKISKAL, $\mathrm{H}$. Dysthymia as a temperamental variant of affective disorder. European Psychiatry, v.11, Supplement 3. 1996. Disponível em: <https://www.sciencedirect.com/science/article/abs/pii/0924933896851856>. DOI: 10.1016/0924-9338(96)85185-6

APA - American Psychiatric Association. Manual diagnóstico e estatístico de transtornos mentais (DSM-V). Trad. Maria Inês Corrêa Nascimento. $5^{\text {a }}$ ed. Porto Alegre: Artmed, 2014.

AVIV, R. The death treatment. When should people with a non-terminal illness be helped to die? The New Yorker. New York, 2015. Disponível em: <https://www.newyorker.com/magazine/2015/06/22/the-death-treatment>. Acesso em: $12 / 05 / 20$.

BLEULER, E. Psiquiatria. 15ª ed. Rio de Janeiro: Guanabara Koogan, 1985.

BORCHART, C. B.; PRUDENTE, A. J. A morte digna como direito fundamental. Revista de Biodireito e Direito dos Animais. Universidade Federal da Bahia (UFBA), $2018 . \quad$ Disponível em: <https://www.researchgate.net/publication/330978025_A_MORTE_DIGNA_COMO DIREITO_FUNDAMENTAL>. DOI: $\quad 10 . \overline{2} 6 \overline{6} 68 /$ IndexLawJournals/25259695/2018.v4i2.5044

BRASIL. Conselho Federal de Medicina (CFM). Resolução CFM no 1.805/2006. Publicada em: 28/11/06. Seção I, p. 169. Brasil, 2006. Disponível em: <http://www.portalmedico.org.br/resolucoes/cfm/2006/1805_2006.htm>. Acesso em: 12/05/20.

BRASIL. Conselho Federal de Medicina (CFM). Código de Ética Médica. Resolução CFM n ${ }^{\circ} 2.217$, de 27 de setembro de 2018, modificada pelas Resoluções CFM no 2.222/2018 e 2.226/2019. Brasil, 2018. Disponível em: $<$ http://www.in.gov.br/materia/-

/asset_publisher/Kujrw0TZC2Mb/content/id/48226289>. Acesso em: 12/05/20.

BRASIL. Presidência da República. Código Penal. Decreto-lei no 2.848, de 7 de dezembro de 1940. Brasil, 1940. Disponível em: 
<http://www.planalto.gov.br/ccivil_03/decreto-lei/del2848compilado.htm>.

Acesso

em:

12/05/20.

BRASIL. Presidência da República. Constituição da República Federativa do Brasil de 1988, promulgada em 5 de outubro de 1988. Brasil, 1988. Disponível em: <http://www.planalto.gov.br/ccivil_03/constituicao/constituicao.htm>. Acesso em: 12/05/20.

BRASIL. Supremo Tribunal Federal (STF). Arguição de Descumprimento de Preceito Fundamental no 54/DF. Rel: Min. Marco Aurélio Mello. Publicada em: 12/04/2012. Distrito Federal, 2012. Disponível em: < http://www.stf.jus.br/arquivo/cms/noticianoticiastf/anexo/adpf54.pdf>. Acesso em: $12 / 05 / 20$.

CARNEIRO, M. S.; RUCHDESCHEL, V. C; GOMES, S. C. J. Desfazendo o nó de Górdio. Um diálogo entre o Direito e a Religião sobre a eutanásia. Caminhando, vol. 24 no 02. Universidade Metodista de São Paulo, 2019. Disponível em: $<$ https://www.meto dista.br/revistas/revistas-ims/index.php/Caminhando/article/view/9759/7079>. DOI: http://dx.doi.org/10.15603/2176-3828/caminhando.v24n2p165-179

COMMISSION FÉDÉRALE DE CONTRÔLE ET D'ÉVALUATION DE L'EUTHANAISE. Huitième rapport aux Chambres législatives années 2016-2017. Belgique, 2017.2 Disponível em: <https://organesdeconcertation.sante.belgique.be/sites/default/files/documents/8_rapporteuthanasie_2016-2017-fr.pdf>. Acesso em: 12/05/20.

CORRÊA, P. Eutanásia e seus conflitos. Jusbrasil, 2019. Disponível em: $<$ https://pedroccorrea.jusbrasil.com.br/artigos/663337450/eutanasia-e-seusconflitos?ref=serp $>$. Acesso em: 12/05/20.

CUNHA, I. Z. O direito à morte digna: fazer viver ou deixar morrer, eis a questão. In: SILVA, M. N. A; MARTEL, L. C. V.; ENGELMANN, W. Biodireito. Organização CONPED/UFF. Florianópolis, FUNJAB, 2012. Disponível em: $<$ http://www.publicadireito.com.br/artigos/?cod=e8855b3528cb03d1>. Acesso em: 15/05/20.

DALL' AGNOL, D. Bioética. 2aㅗ ed. Rio de Janeiro: Jorge Zahar Editor, 2015.

DIAS, M. B. Bioética e Direito. Conteúdo Jurídico. Brasília, 2009. Disponível em: $<$ https://www.conteudojuridico.com.br/consulta/Artigos/16295/bioetica-e-direito>. Acesso em: 12/05/20.

FELIX, Z. C.; COSTA, S. F. G.; ALVES, A. M. P.; ANDRADE, C. G.; DUARTE, M. C. $S$. et al. Eutanásia, distanásia e ortotanásia: revisão integrativa da literatura. Ciência e Saúde coletiva, vol.18 ㄲo.9. Núcleo de Estudos e Pesquisas em Bioética, Universidade Federal da 2013. <https://www.scielosp.org/article/csc/2013.v18n9/2733-2746/>. DOI: 10.1590/S141381232013000900029

FRANÇA, G. V. Direito Médico. 15ª ed, Rio de Janeiro: Forense, 2019. 
GRIFFITHS, J.; RAVINDRAN, A. V.; MERALI, Z.; ANISMAN, H. Dysthymia: a review of pharmacological and behavioral factors. Mol Psychiatry, 2000. Disponível em: <https://www.nature.com/articles/4000697>. DOI: 10.1038/sj.mp.4000697

HEIDEGGER, M. Ser e tempo. Trad. Marcia Sá Cavalcante Schuback. $10^{\mathrm{a}}$ ed. Petrópolis: Vozes, 2015.

KANT, Immanuel. Metafísica dos costumes. Trad. Clélia Aparecida Martins. Trad. (2 $2^{\mathrm{a}}$ parte) Bruno Nadai, Diego Kosbiau e Monique Hulshof. Rio de Janeirto: Vozes, 2013.

KORNSTEIN, S. G.; SCHATZBERG, A. F.; THASE, M. E.; YONKERS, K. A.; KEITNER, G. I. et al. Gender differences in chronic major and double depression. Journal of Affective Disorders, 2000. Disponível em: <https://www.sciencedirect.com/science/article/abs/pii/S0165032799001585?via\%3D ihub>. DOI: 10.1016/s0165-0327(99)00158-5

KORNSTEIN, S. G. Chronic Depression in Women. J Clin Psychiatry, Vol 63, No 7. $2002 . \quad$ Disponível em: <https://www.psychiatrist.com/JCP/article/Pages/2002/v63n07/v63n0713.aspx>. DOI: 10.4088/jcp.v63n0713

LORDA, P. S.; CANTALEJO, I.M. B. La eutanásia em Bélgica. Rev Esp Salud Pública, vol 86 oㅜ 01. Escuela Andaluza de Salud Pública. Granada, 2012. Disponível em: <http://scielo.isciii.es/scielo.php?script=sci_arttext\&pid=S113557272012000100002>. Acesso em: 12/05/20.

MARMELSTEIN, G. Curso de direitos fundamentais. $8^{\text {a }}$ ed. São Paulo: Atlas, 2019.

MATOS, E. G.; MATOS, T. M. G.; MATOS, G. M. G. Depressão melancólica e depressão atípica: aspectos clínicos e psicodinâmicos. Estudos de Psicologia, vol. 23 no2. Pontifícia Universidade Católica de Campinas (PUCCAMP), 2006. Disponível em: $<$ https://www.scielo.br/scielo.php?pid=S0103166X2006000200007\&script=sci_arttext>. DOI: 10.1590/S0103$166 \times 2006000200007$.

MELO, M. T. A eutanásia, a ortotanásia e a distanásia à luz da justiça brasileira. Âmbito Jurídico, 2016. Disponível em: <https://ambitojuridico.com.br/edicoes/revista155/a-eutanasia-a-distanasia-e-a-ortotanasia-a-luz-da-justica-brasileira/>. Acesso em: 12/05/20.

MORENO, R; MORENO, D. A relação entre outros quadros psiquiátricos e distimia. In: CORDÁS, T.A; MORENO, R. A; NARDI, A. E. Distimia - do mau humor ao mal do humor. Porto Alegre: Artes Médicas, 1997.

MORIN, E. EI hombre e la muerte. Barcelona: Kairós, 1974.

NESSE, R. M. Is Depression an Adaptation? The Archives of General Psychiatry, Vol 57:14-20. Department of Psychiatry. The University of Michigan, 2000. 
Disponível em: <https://jamanetwork.com/journals/jamapsychiatry/articleabstract/481547>. DOI: 10.1001/archpsyc.57.1.14

OLIVEIRA, T. Governo federal lança campanha de valorização da vida e de combate à depressão. Brasil: Agência Saúde - Ministério da Saúde. Governo Federal, 2019. Disponível em: <https://saude.gov.br/noticias/agencia-saude/45805governo-federal-lanca-campanha-de-valorizacao-da-vida-e-de-combate-adepressao >. Acesso em: 12/05/20.

ONU - Organização das Nações Unidas. Declaração Universal sobre Bioética e Direitos Humanos. Comissão Nacional da UNESCO. $3^{\text {a }}$ sessão da Conferência Geral da UNESCO. Portugal, 2005. Disponível em: <https://unesdoc.unesco.org/ark:/48223/pf0000146180_por>. Acesso em: 12/05/20.

ONU - Organização das Nações Unidas. Declaração Universal dos Direitos Humanos. Assembleia Geral das Nações Unidas. Paris,1948. Disponível em: $<\mathrm{https}: / /$ nacoesunidas.org/wp-content/uploads/2018/10/DUDH.pdf>. Acesso em: 12/05/20.

OPAS - Organização Pan Americana de Saúde. Folha informativa - Depressão, $2018 . \quad$ Disponível em: $<$ https://www.paho.org/bra/index.php?option=com_content\&view=article\&id=5671:fol ha-informativa-suicidio\&ltemid=839>. Acesso em: 15/05/20.

PRESSLY, L. Eutanásia: a jovem com problemas psiquiátricos que conseguiu ajuda dos médicos para morrer. Da Holanda para a BBC News. Holanda, 2018. Disponível em: <https://www.bbc.com/portuguese/geral-45144669>. Acesso em: 12/05/20.

RIDOLPHI, A. C.; RANGEL, T. L. Morte digna à luz da dignidade da pessoa humana: o direito de morrer. Boletim Jurídico, a. 28, no 1479. Uberaba/MG, 2017. Disponível em: $\quad$ https://www.boletimjuridico.com.br/artigos/cronicas/3736/morte-digna-luzdignidade-pessoa-humana-direito-morrer>. Acesso em: 12/05/20.

SADOCK, V. A.; SADOCK, B. J; RUIZ, P. Compêndio de psiquiatria: ciências do comportamento e psiquiatria clínica. $11^{\mathrm{a}}$ ed. Porto Alegre: Artmed, 2016.

SPANEMBERG, L; JURUENA, M. F. Distimia: características históricas e nosológicas e sua relação com transtorno depressivo maior. Revista de Psiquiatria do Rio Grande do Sul, v.26 n.3. Porto Alegre, 2004. Disponível em: $<$ https://www.scielo.br/scielo.php?script=sci_arttext\&pid=S0101$81082004000300007 \&$ Ing=pt\&tlng=pt>. DOI: $10.1590 /$ S0101-81082004000300007

SULLIVAN, P. F.; KESSLER, R. C.; KENDLER, K. S. Latent class analysis of lifetime depressive symptoms in the national comorbidity survey. The American Journal of Psychiatry, $1998 . \quad$ Disponível em: <https://ajp.psychiatryonline.org/doi/full/10.1176/ajp.155.10.1398>. DOI: 10.1176/ajp.155.10.1398 
TUCHLINSKI, C. Depressão será a doença mental mais incapacitante do mundo até 2020. São Paulo: O Estado de São Paulo, 2018. Disponível em: <https://emais.estadao.com.br/noticias/bem-estar,depressao-sera-a-doenca-mentalmais-incapacitantes-do-mundo-ate-2020,70002542030 >. Acesso em: 15/05/20.

URUGUAI. Código Penal. Lei 9414, de 29 de junio de 1934. Uruguai, 1934. Disponível em: <https://www.ufrgs.br/bioetica/penaluru.htm>. Acesso em: 15/02/20.

VISMARI, L.; ALVES, G. J.; NETO, J. P. Depressão, antidepressivos e sistema imune: um novo olhar sobre um velho problema. Revista de Psiquiatria Clínica, v. 35 no 05. Faculdade de Medicina da Universidade de São Paulo, 2008. Disponível em: $<$ https://www.scielo.br/scielo.php?pid=S0101$60832008000500004 \&$ script=sci_arttext\&tlng=pt>. $\quad$ DOI: $10.1590 / S 0101-$ 60832008000500004 .

WESTERMEYER, J.; EAMES, S. L.; NUGENT, B. S. Comorbid dysthymia and substance disorder: treatment history and cost. The American Journal of Psychiatry, vol 155 issue 11, 1998. Disponível em: <https://ajp.psychiatryonline.org/doi/full/10.1176/ajp.155.11.1556>. $\quad$ DOI: 10.1176/ajp.155.11.1556

WHO - World Health Organization. International classification of diseases for mortality and morbidity statistics, 11th Revision (ICD-11). 2018. Disponível em: $<$ https://icd.who.int/browse11/l-m/en>. Acesso em: 12/05/20. 